\title{
pro.posições
}

$e$-ISSN 1980-6248

http://dx.doi.org/10.1590/1980-6248-2015-0164

ARTIGOS

\section{Conceito de ser humano nas teorias de enfermagem: aproximação com o ensino da condição humana}

\section{The concept of the human being in nursing theories: establishing a relationship with the teaching of the human condition}

\author{
Anaísa Cristina Pinto ${ }^{(i)}$ \\ Mara Lúcia Garanhani (ii) \\ Thiago Eduardo de França (iii) \\ Isadora Pierotti (iv)
}

\begin{abstract}
(i) Grupo de pesquisa Enfermagem e Políticas da Saúde Mental (GEnPSM), Escola de Enfermagem, Universidade de São Paulo - USP, São Paulo, SP, Brasil, anaisacristina@gmail.com.

(ii) Universidade Estadual de Londrina -UEL, Londrina, PR, Brasil, maragara@hotmail.com.

(iii) Projeto Casa do Pequeno Cidadão - PCPC, Matão, SP, Brasil, thiagofranca07@gmail.com.

(iv) Centro de Ciências da Saúde, Curso de Enfermagem, Universidade Estadual de Londrina - UEL, Londrina, PR, Brasil, isa_pierotti@hotmail.com.
\end{abstract}

Resumo: Este estudo relacionou os conceitos sobre o ser humano, propostos pelas teoristas de enfermagem, com o ensino da condição humana defendido por Edgar Morin. Isso é pertinente ao contexto educacional, já que as teoristas de enfermagem são parte do arcabouço teórico da profissão e Morin é influente no âmbito educacional. Para isso foi feita uma análise de abordagem qualitativa, descritiva e exploratória. Nos resultados foram englobadas 21 teoristas expostas no livro Teorias de enfermagem: os fundamentos para a prática profissional e Wanda Aguiar Horta, localizada no livro "Processo de enfermagem". Concluiu-se que as teoristas estabeleceram conhecimentos que orientam a prática do enfermeiro para a formação da consciência da condição humana, necessária à diversidade e que permite o desenvolvimento do cuidado humano.

Palavras-chave: educação em enfermagem, formação de conceito, humanos, teoria de enfermagem 


\section{pro.posições}

$e$-ISSN 1980-6248

http://dx.doi.org/10.1590/1980-6248-2015-0164

Abstract: This research correlates the concepts of the human being proposed by the nursing theorists with the teaching of the human condition supported by Edgar Morin. Such proposal is pertinent to the educational context as nursing theorists are part of the profession's theoretical framework and Morin is influential in the educational ambit. A qualitative, descriptive and exploratory analysis was performed to achieve the present outcomes. The results encompassed 21 theorists presented in the book Teorias de enfermagem: os fundamentos para a prática profissional (Nursing theories: The fundamentals of a professional practice), as well as Wanda Aguiar Horta, from the book Processo de Enfermagem (Nursing process). It was concluded that these theorists established a knowledge that guides the nursing practise towards the formation of an awareness of the buman condition, which is necessary for the diversity that allows for the development of human care.

Keywords: nursing education, concepts formation, bumans, nursing theory

\section{Introdução}

Edgar Morin é um pensador contemporâneo, de grande impacto na Educação. O seu principal foco de estudo é a teoria da complexidade, constituída por diversos aspectos. As reflexões do pensador influenciam os vários âmbitos do ensino e podem repercutir na construção de Projetos Político-Pedagógicos (PPP) de escolas.

Os PPP, dentre as suas diversas atribuições, orientam as ações educativas desenvolvidas pelo microssistema escolar, influenciadas pelo macrossistema social, expressando uma "concepção clara de educação e de escola, de sociedade, de conhecimento e de visão humana" (Sitó, 2005, p.3). Desse modo, implantar e implementar um PPP exige um movimento complexo, que une diversas partes em uma teia de relações (Morin, 2005; Sitó, 2005).

Os PPP dos cursos universitários assumem definições de conceitos que acreditam importantes para a formação profissional, na busca em atender às demandas do campo do trabalho, da produção de conhecimento e da formulação de políticas públicas da Educação. Muitas escolas de enfermagem assumem conceitos para direcionar a formação profissional e um deles é o conceito de ser humano. Incorporar essa concepção no direcionamento da prática educativa é pertinente quando consideramos que a educação é desempenhada com seres humanos, a partir da visão que se tem deles (Fernandes \& Rebouças, 2013).

Outra grande influência para a formulação do PPP de cursos de enfermagem são as teorias de enfermagem. Elas surgiram pela preocupação em construir um corpo de 


\section{pro.posições}

$e$-ISSN 1980-6248

http://dx.doi.org/10.1590/1980-6248-2015-0164

conhecimento e instrumental próprios, que consolidassem a enfermagem como profissão na busca de autonomia, permitindo que se delimitassem as funções do enfermeiro diante do trabalho de outros profissionais de saúde (Almeida et al, 2009; Ângelo, Forcella \& Fukuda, 1995).

A articulação e a sistematização de novas visões teórico-filosóficas no campo da enfermagem ganharam força a partir da década de 1950. Nesse período, nos Estados Unidos da América (EUA), a enfermagem era inserida entre as carreiras de nível superior. A partir de então, devido às exigências na carreira universitária, cresceu o número de enfermeiros com título de mestrado e doutorado. A exigência de pós-graduação aproximou as enfermeiras do mundo da Filosofia da Ciência propiciando reflexões mais aprofundadas sobre a natureza da enfermagem e seus propósitos (Garcia \& Nóbrega, 2004).

O marco referencial do surgimento das teorias de enfermagem se deu em 1952, com a publicação do livro de Hildegard Peplau, que abordava o relacionamento interpessoal na enfermagem. Desde então, os caminhos para novas teoristas foram abertos e enfermeiras norteamericanas passaram a desenvolver e publicar, sob diferentes pontos de vistas filosóficos, novas teorias de enfermagem. A divulgação e a utilização dessas teorias não se limitaram apenas à enfermagem norte-americana, romperam fronteiras, estimularam e influenciaram a formulação de teorias de enfermagem em outros países (Garcia \& Nóbrega, 2004).

No Brasil, Wanda de Aguiar Horta, por meio de sua obra, foi a primeira enfermeira a discutir sobre teorias de enfermagem e a estimular o interesse sobre o assunto. Divulgou, com seus trabalhos, as teorias elaboradas pelas enfermeiras norte-americanas e, a posteriori, em 1974, elaboraria e divulgaria a Teoria das Necessidades Humanas Básicas (Garcia \& Nóbrega, 2004).

Em geral, as teorias de enfermagem são estruturadas em torno de quatro conceitos essenciais: ser humano, saúde, meio ambiente e enfermagem. Assim, é relevante considerar o conhecimento produzido em torno dessas concepções, e em especial o primeiro, já que o compromisso social da profissão alia o cuidado às experiências humanas (Schaurich \& Crossetti, 2010; Thofehrn \& Leopardi, 2002).

As teorias de enfermagem incorporadas na elaboração de currículos favorecem o desenvolvimento de uma educação crítica, que abarca as questões relacionadas à integralidade da saúde (Silva, 2014). 


\section{pro.posições}

$e$-ISSN 1980-6248

http://dx.doi.org/10.1590/1980-6248-2015-0164

Em 1999 a Organização das Nações Unidas para a Educação, a Ciência e a Cultura (UNESCO) convidou Edgar Morin para sistematizar reflexões que fundamentariam o contexto educacional do milênio conseguinte. Esse convite resultou no livro Os sete saberes necessários para a educação do futuro, cujo discurso pondera sobre a necessidade de que haja um esforço transdisciplinar capaz de unir as ciências e as humanidades e romper com o paradoxo natureza/cultura (Morin, 2011).

Dentre os sete saberes necessários para a educação do futuro temos o intitulado "Ensinar a condição humana", encontrado no terceiro capítulo do livro (Morin, 2011). Esse saber foi selecionado para discutir os resultados alcançados com este estudo.

Este artigo pretende aproximar do conceito de ser humano defendido pelas teoristas de enfermagem, as bases teóricas do ensino da condição humana proposto por Morin (2011). Essa aproximação é pertinente ao contexto educacional da atualidade, uma vez que as teoristas de enfermagem constituem elementos significativos do arcabouço teórico da profissão e Edgar Morin é influente no âmbito da Educação.

Dessa maneira, este estudo tem como questão norteadora: Qual é a relação entre os conceitos de ser humano defendidos pelas teoristas de enfermagem, e os propostos por Edgar Morin, ao apresentar o ensino da condição humana?

Para que se responda a essa indagação, estabelecemos o seguinte objetivo: relacionar os conceitos sobre o ser humano propostos pelas teoristas de enfermagem com o ensino da condição humana, defendido por Edgar Morin.

\section{Referencial teórico}

Como referencial teórico deste estudo, utilizamos o "Ensino da condição humana" de Morin (2011). Ressalvamos que não houve o intuito de separar uma parte do todo escrito por Morin. Sabemos que isso é contraditório ao pensamento complexo, que não possui caráter disjuntivo. Contudo, faz sentido para este estudo utilizar esse capítulo, que é mais condizente com o objetivo proposto. Nos parágrafos seguintes, apresentamos uma síntese do assunto tratado nesse capítulo do livro. 


\section{pro.posıções}

$e$-ISSN 1980-6248

http://dx.doi.org/10.1590/1980-6248-2015-0164

Ainda que, no século XX, muitos conhecimentos esclareçam a posição do ser humano no universo, eles permanecem desconectados. Não é possível conceber a complexidade humana por um pensamento que não una as partes. Isso porque, quando há avanços nos saberes dos fragmentos sem o esforço de religá-los, se permanece estático no conhecimento do todo (Morin, 2011). A educação do futuro exige que haja um entrelaçamento dos saberes e que o ser e a sua condição humana, sejam situados no mundo, evidenciando o seu caráter complexo e multidimensional (Morin, 2011). Para isso, segundo Morin, três questões precisam ser evidenciadas:

A primeira está relacionada ao enraizamento/desenraizamento bumano. Ela diz respeito ao fato de estarmos simultaneamente dentro e fora da natureza, como seres ao mesmo tempo cósmicos, físicos e terrestres, que devem assumir a sua identidade terrena, física e biológica (Morin, 2011). A força cósmica da organização/religação evitou que o cosmos se dissipasse e se apagasse ao nascer. A vida surgiu de substâncias físicas que se organizaram termodinamicamente sobre a Terra, a qual, por sua vez, se autoproduziu e se auto organizou na dependência do Sol. Compôs-se em um complexo biofísico, a partir do momento em que se desenvolveu a biosfera. A vida evoluiu tanto nas espécies como nos ecossistemas, onde a cadeia trófica constitui a dupla face da existência: a vida e a morte (Morin, 2011).

O segundo aspecto refere-se às características bumano do bumano. Nesse ponto, Morin defende o ser como unidual. Isso quer dizer que ele é, ao mesmo tempo, plenamente biológico e cultural com características antagônicas e complementares. Assim, o ser humano é concomitantemente Homo sapiens e Homo demens, na medida em que exprime, de maneira hipertrofiada, as qualidades egocêntricas e altruístas do indivíduo. O homem é um ser plenamente biológico, mas se não fosse a cultura, seria um primata. Ele só se realiza por inteiro como ser humano pela e na cultura. Nesse aspecto, o autor apresenta três tríades como constituintes do ser humano: mente/cérebro/cultura, razão/afeto/pulsão e indivíduo/sociedade/espécie (Morin, 2011).

A primeira diz respeito ao fato de não haver cultura sem o cérebro humano, e não existir mente - capacidade de consciência - sem a cultura. A mente intervém no funcionamento cerebral e retroage sobre ele. O termo razão/afeto/pulsão aponta que existe, ao mesmo tempo, a relação complementar e antagônica entre as três instâncias. Em relação à terceira tríade, Morin defende que a sociedade vive para o indivíduo, que vive para a sociedade, que os dois vivem 


\section{pro.posições}

$e$-ISSN 1980-6248

http://dx.doi.org/10.1590/1980-6248-2015-0164

para a espécie, e que ela vive para os dois. Os três termos são, de modo simultâneo fim e meio do existir (Morin, 2011).

A terceira questão evidenciada por Morin relaciona-se às unitas multiplex, ou seja, à unidade e à diversidade humanas. Nesse ponto, o autor indica que a educação do futuro não pode deixar que a ideia da unidade da espécie humana apague a ideia da diversidade, e viceversa. A educação deve ilustrar esses princípios nas esferas: individual; social; diversidade cultural/pluralidade de indivíduos; homo sapiens/demens; e homo complexus (Morin, 2011). Essas esferas humanas sugerem:

Individual: que o ser humano carregue seus genes, compreenda geneticamente a singularidade anatômica/fisiológica própria e que exista a unidade/diversidade genética; social: que haja uma unidade/diversidade nas organizações sociais, nas culturas e nas línguas; diversidade cultural/ pluralidade de indivíduos: que a cultura seja transposta pelas gerações, se produza em cada indivíduo, controle a existência da sociedade e mantenha a complexidade psicológica e social; homo sapiens/demens: que o século XXI abandone a visão unilateral que define o ser humano pela racionalidade, pela técnica, pelas atividades utilitárias e pelas necessidades obrigatórias e assuma o humano como um ser complexo, que carrega, ao mesmo tempo, características bipolarizadas, como a sabedoria (sapiens) e a loucura (demens). A dialógica sapiens/demens é criadora e destruidora, pois demens inibe e favorece sapiens (Morin, 2011); homo complexus: que o ser humano seja abordado como aquele que apresenta características antagônicas, não sendo completamente prisioneiro do real, da lógica. A pesquisa e a descoberta avançam no vácuo da incerteza e da incapacidade de decidir. O gênio brota na brecha do incontrolável, justamente onde a loucura ronda (Morin, 2011).

\section{Trajetória metodológica}

Este é um artigo de abordagem qualitativa, que utilizou a análise documental do corpo de conhecimento de teoristas de enfermagem e apoiou-se no referencial teórico "ensino da condição humana", de Edgar Morin. 


\section{pro.posições}

$e$-ISSN 1980-6248

http://dx.doi.org/10.1590/1980-6248-2015-0164

O período de análise documental ocorreu entre os meses de fevereiro e março de 2014. Essa fase constituiu-se de leitura exploratória, leitura seletiva, leitura analítica/agrupamento e leitura interpretativa do material (Gil, 2002).

Para selecionar os conceitos acerca do ser humano, no corpo de conhecimento das teorias de enfermagem, foram elencadas as teoristas descritas no livro Teorias de enfermagem: os fundamentos para a prática profissional, de Julia B. George, nas edições de 1993 e 2000, ou seja, as teoristas que apareciam somente em uma das duas versões não foram utilizadas. Optamos por trabalhar com esse compêndio, por ser a versão traduzida das teorias internacionais e por ser bastante utilizado pelas escolas de enfermagem brasileiras. Além das teoristas descritas no livro citado, também foi incluída neste estudo Wanda Aguiar Horta, autora da "Teoria das necessidades bumanas básicas", desenvolvida no livro Processo de enfermagem (Horta, 1979). A inclusão de Horta neste estudo se justifica pelo fato de a autora ser uma influente teorista brasileira, criadora do modelo teórico mais conhecido e utilizado no País (Pires, Meier \& Danski, 2011), inclusive na formulação de PPP de cursos de enfermagem (Dell'Aqua \& Miyadahira, 2002; Horr, Gonçalves \& Saupe, 1987).

Selecionado o material para análise, prosseguimos para a forma de utilização dele. Em um primeiro momento, foi feita a leitura exploratória, para constatar a importância da obra para a pesquisa e, então, a leitura seletiva e o grifo do conteúdo, destacando o que era pertinente aos objetivos da pesquisa. Não houve a intencionalidade de esgotar todo o corpo de conhecimento sobre a teoria, entretanto se tomou cuidado para não descontextualizar os discursos.

Em seguida foram realizadas a leitura analítica do material, de modo a sintetizar as ideias de cada teorista, e a leitura interpretativa dele. Nessa ocasião, foram reescritas todas as definições para cada teorista acerca do ser humano. Por fim, foram refletidos os conceitos encontrados, à luz do ensino da condição humana de Edgar Morin. A partir dessa análise, emergiram ponderações voltadas para a formação do enfermeiro.

Houve limitações no processo de análise documental das teorias de enfermagem. Os conceitos acerca do ser humano nem sempre estavam explícitos em todas elas. Isso exigiu a leitura de toda a obra da teorista, exposta no livro de consulta, a fim de compreender o conceito de ser humano subentendido em suas ideias. Muitas vezes, esse conceito estava implícito e era encontrado permeando outras definições. 


\section{pro.posıções}

$e$-ISSN 1980-6248

http://dx.doi.org/10.1590/1980-6248-2015-0164

Outra limitação deste estudo foi o fato de não terem sido apontados os momentos históricos nos quais as teorias emergiram, trazendo concepções de ser humano isentas de historicidade. É sabido que, ao longo de suas jornadas, as teoristas realizaram adaptações, sínteses e ajustes em suas propostas teóricas, porém não foi objetivo deste estudo apontar essas reformulações. É importante indicar esse limite do presente estudo, para que não se afirme que as concepções sobre o ser humano das teorias abordadas são fixas e imutáveis. É de ciência que o ideal é que não se perca de vista a totalidade do conteúdo das teorias. Este estudo não teve a intenção de desrespeitar a complexidade de cada uma delas. A tentativa de não fragmentar a teoria, na busca de uma ideia específica na completude da obra, foi um obstáculo encontrado no processo de desenvolvimento deste estudo. Houve a tentativa de transposição desse entrave na elaboração deste artigo, de modo a não ferir a singularidade de cada uma das teorias.

\section{Resultados}

A análise do material resultou na síntese dos principais aspectos relacionados ao ser humano abordado por cada teorista de enfermagem:

Florence Nightingale: Descreve o ser humano em termos de processo de cura. A sociedade/ambiente exerce impacto sobre o processo saúde doença e sobre o profissional enfermeiro, que reconfigura o seu modo de cuidar. Isso afeta o indivíduo e sua maneira de lidar com o adoecimento. Para ela, o ambiente exerce influência sobre a condição humana (Lobo, 2000a).

Hildegard Peplau: Refere-se ao ser humano como um organismo que luta para reduzir as tensões geradas por suas necessidades. Para ela, as pessoas são estruturas biopsicossocioespirituais únicas, que aprendem de maneiras diferentes, a partir do ambiente/cultura em que estão inseridas. Dessa maneira, uma nunca reagirá do mesmo modo que a outra. Elas interagem pelas suas ideias preconcebidas, que influenciam nas suas percepções sobre as coisas. Essas diferentes compreensões são importantes para as relações interpessoais (Belcher \& Fish, 2000). 


\section{pro.posıções}

$e$-ISSN 1980-6248

http://dx.doi.org/10.1590/1980-6248-2015-0164

Virgínia Henderson: Defende que os seres humanos são compostos por elementos biopsicossocioespirituais e possuem necessidades básicas, satisfeitas por diferentes padrões de vida (Furukawa \& Howe, 2000).

Evelyn Adam: Define seis unidades principais em seu modelo conceitual (baseado em Henderson). O beneficiário é a pessoa ou grupo para quem está voltada a atividade profissional. A teorista defende que a meta da enfermagem é a busca da manutenção e da recuperação da independência do cliente, para satisfazer as suas necessidades biopsicossocioculturais. Quando essas necessidades não são satisfeitas, a pessoa não está emancipada (George, 2000c).

Lydia E. Hall: Pondera sobre o ser humano como um indivíduo único e capaz de crescer e aprender. A fonte de energia para cura é de quem recebe o cuidado, e não de quem oferece. Sua teoria exige a abordagem da pessoa total (George, 2000g).

Dorothea E. Orem: Defende que os seres humanos apresentam um funcionamento que integra aspectos físicos, psicológicos, interpessoais e sociais. As suas experiências de vida levam à criação de símbolos, que os fazem refletir sobre si mesmos e sobre o ambiente em que estão inseridos. Essa capacidade os difere dos demais seres vivos. Os indivíduos têm potencial para a aprendizagem e para o desenvolvimento. O ser humano pode ser percebido por duas diferentes perspectivas. Na primeira, focaliza as pessoas evoluindo na direção do amadurecimento e da realização do potencial humano. $\mathrm{Na}$ segunda, enfoca a diferença entre estrutura e função da unidade humana. Contudo, Orem enfatiza que ambas as perspectivas precisam integrar-se para uma enfermagem eficaz (Foster \& Bennett, 2000).

Dorothy E. Johnson: Diz que os humanos são seres constituídos pelo sistema biológico - foco da medicina - e pelo comportamental - foco da enfermagem -, ambos influenciados pelos acontecimentos do ambiente, inclusive os culturais. Quando há alguma disfunção em um dos dois sistemas, ações recíprocas entre eles ocorrem. A meta do indivíduo é manter a estabilidade dos sistemas físico, mental, emocional e social (Lobo, 2000b).

Betty Jo Hadley: Descreve ser humano como um ser biopsicossocial, que padroniza maneiras de alcançar metas e de enfrentar estresses cotidianos. O rompimento com esses padrões causa doenças, que leva o ser humano a procurar os serviços de saúde. Essa mudança de ambiente gera estresses, que podem ocasionar distorção da imagem corporal, sobrecarga 


\section{pro.posıções}

$e$-ISSN 1980-6248

http://dx.doi.org/10.1590/1980-6248-2015-0164

sensorial, privação afetiva, imobilidade, incapacidade para satisfazer as necessidades pessoais, incoerência perceptiva e instabilidade bioquímica (George, 2000a).

Faye Glenn Abdellah: Não traz perspectiva estruturada sobre o ser humano, porém considera que eles e suas famílias são objetos do cuidado de enfermagem. Apresenta 21 problemas que abordam as áreas biológica, psicológica e social dos indivíduos (Falco, 2000).

Ida Jean Orlando: Refere-se aos seres humanos como recebedores de cuidado. Cada pessoa é diferente, e as ações de enfermagem devem ser individualizadas. Os enfermeiros precisam sempre certificar suas ações diante das necessidades dos pacientes, quando eles não conseguirem. Utiliza o conceito de humano à medida que enfatiza a individualidade e a natureza dinâmica da relação enfermeiro-paciente (George, 2000d; Leonard, 2000).

Ernestine Wiedebach: Afirma que o ser humano possui potencial único e esforça-se no sentido da autodireção e da independência/autonomia. Além disso, necessita de estímulos para desenvolver as suas habilidades e autoestima, sendo necessárias autoconscientização e autoaceitação. As suas decisões representam o seu melhor juízo no momento. Tais características exigem respeito por parte do enfermeiro (Bennett \& Foster, 2000).

Myra Estrin Levine: Enxerga o ser humano de forma holística, o que implica aceitá-lo como um ser complexo. Seres humanos são sociais, conscientes, racionais, perceptivos, controladores, intencionais, voltados à ação e ao tempo. São dependentes da relação com o outro, no que se refere aos aspectos de sobrevivência, como: alimentação, segurança, recreação, diversão e associação (Leonard, 2000).

Imogene King: Diz que os seres humanos se constituem sistemas abertos, que interagem constantemente com o seu meio ambiente. Existem três tipos de sistemas: os pessoais, os interpessoais e as comunidades/sociedades. O primeiro é representado pelos próprios indivíduos, que vivenciam as situações de maneira única. Os processos de interação humana com o ambiente influenciam o comportamento e dão significado à experiência. Alguns conceitos relevantes desse sistema são: a percepção universal, que é experimentada por todos, subjetiva ou pessoal e seletiva para cada pessoa; o self, que trata do interior de cada pessoa; o crescimento e o desenvolvimento; a imagem corporal e o espaço. Os sistemas interpessoais abordam a interação desses indivíduos em duplas, pequenos ou grandes grupos, através de 


\section{pro.posições}

http://dx.doi.org/10.1590/1980-6248-2015-0164

\section{$e$-ISSN 1980-6248}

comunicação verbal/não verbal. E, as comunidades e as sociedades são organizações com interesses comuns (George, 2000e).

Martha E. Rogers: Vê a enfermagem como uma ciência humanística. O ser humano caracteriza-se pela capacidade de abstração e imaginação, pela linguagem e pensamento, pela sensação e emoção. De todas as formas terrestres, apenas a humana é consciente, pensante, e percebe a vastidão do cosmo e pondera sobre ela. O ser humano é visto como um todo unificado, que possui integridade individual e manifesta características que são mais que a soma das partes e diferentes delas. As propriedades distintas do todo são também significantemente diferentes daquelas de suas partes. O ser humano só se torna visível quando as partes somem de vista e a sua totalidade fica evidente. Essa, por sua vez, constitui o processo vital do indivíduo. É um curso dinâmico, contínuo, criativo, evolutivo e incerto que resulta em um padrão variável e em constante modificação. Para Rogers, identificar indivíduos e refletir a sua totalidade são a base dos padrões de vida. Esses padrões permitem a autorregulamentação, a ritmicidade e o dinamismo. Eles dão unidade à diversidade e refletem um universo dinâmico e criativo. O ser humano troca matéria e energia com o ambiente de forma contínua, caracterizando-os como sistemas abertos. A teorista também aborda questões relacionadas a tempo e espaço. Para ela, o processo de vida dos seres humanos é irreversível e unidirecional. Em qualquer determinado ponto no tempo, o indivíduo é a expressão da totalidade de eventos presentes, naquele determinado período (Falco \& Lobo, 2000).

Joyce Fitzpatrick: Aponta que o humano é um ser unitário maior do que a soma de suas partes. A totalidade humana acha-se refletida em padrão e organização. O ser humano é capaz de sentir, experimentar emoção, pensar, utilizar a linguagem, lidar com a imaginação e com a abstração. Ele e o ambiente são sistemas abertos, que intercambiam continuamente matéria e energia ao longo do espaço-tempo. O desenvolvimento humano é um processo caracterizado por ritmos e baseado em significados pessoais. A saúde é encarada como uma característica dos humanos. Ela está em contínuo desenvolvimento e apresenta o potencial total da vida. Esse, por sua vez, pode caracterizar o processo de morte, a expressão mais elevada do sentido da vida, representando a dimensão mais desenvolvida de saúde. O cuidado de enfermagem deve intensificar o processo de desenvolvimento, na direção da saúde, e estimular os indivíduos para a expansão do seu potencial como seres humanos (George, 2000f). 


\section{pro.posições}

http://dx.doi.org/10.1590/1980-6248-2015-0164

\section{$e$-ISSN 1980-6248}

Callista Roy: Defende que as pessoas são sistemas vivos em constante interação, troca de informações, matéria e energia com seus ambientes. Isso resulta em mudanças internas e externas. Essa característica dos sistemas vivos é chamada de abertura. A variação de estímulos à qual a pessoa pode reagir adaptativamente com simples esforço está em constante mudança, sendo influenciada pelos mecanismos de enfrentamento de cada um. Roy considera a identidade de quem recebe o cuidado, seja pessoa, família, grupo, comunidade ou sociedade. Para ela, cada um é um sistema holístico e adaptativo, e os aspectos individuais agem para formar um ser unificado. Os comportamentos são feedbacks para o ser humano e podem ser respostas adaptativas ou ineficientes para a pessoa. Os processos de enfrentamento são herdados ou genéticos, bem como os mecanismos de controle, que são sistemas adaptativos e podem ser reguladores ou cogniscentes. O subsistema regulador possui os componentes que se originam interna ou externamente, e seus transmissores são fisiológicos. O subsistema cogniscente envolve estímulos que também podem ser internos ou externos, mas o controle está ligado ao processamento de percepções ou informações, julgamentos e emoções. Os dois subsistemas agem frequentemente juntos. O nível de adaptação da pessoa é influenciado pelo seu desenvolvimento e pelo uso desses sistemas de enfrentamento (Galbreath, 2000).

Betty Neuman: Afirma que o ser humano é total, multidimensional, composto de variáveis fisiológicas, psicológicas, socioculturais, espirituais e de desenvolvimento. Os conceitos não são trabalhados isoladamente, são relacionados com o todo que, para ela, é diferente da soma das partes. Pessoas interagem constantemente com o ambiente à sua volta em qualquer ponto do tempo. $\mathrm{O}$ ambiente é intra, inter e extrapessoal e opera no sistema do ser humano. Ele, por meio de um processo de interação, retém graus variados de equilíbrio e harmonia entre os ambientes internos e externos. A enfermagem tem como meta conservar a energia, esteja o paciente na direção do bem-estar ou da doença (George, 2000b).

Josephine E. Paterson e Loretta T. Zderad: Argumentam que o ser humano é aberto às opções e apresenta manifestações únicas do seu passado, presente e futuro. Ele é existencial em um movimento de vir a ser pelas suas escolhas e relaciona-se com outros homens no tempo e no espaço, onde se constitui como ser. Isso permite que a individualidade de cada pessoa seja concretizada. As autoras defendem a prática da enfermagem humanística (Praeger, 2000).

Jean Watson: Diz que o ser humano é maior do que a soma das partes e diferente delas. É um ser valorizado em si e de si e deve ser atendido, respeitado, zelado, compreendido e 


\section{pro.posições}

http://dx.doi.org/10.1590/1980-6248-2015-0164

$e$-ISSN 1980-6248

auxiliado. Apresenta uma visão filosófica do homem como ser totalmente integrado e funcional. Os conflitos de desenvolvimento são basicamente psicossociais e representam crises e momentos decisivos da vida humana, o que pode gerar estresses que exijam respostas de enfrentamento. A atenção sistemática a esses conflitos do indivíduo e de suas famílias é necessária ao cuidado de saúde (Talento, 2000)

Rosemarie Rizzo Parse: Relaciona as estruturas teóricas Homem-Vida-Saúde. Ela sintetiza os conceitos de Rogers e os princípios do pensamento existencial/fenomenológico, nos seguintes dogmas: intencionalidade, subjetividade humana, coconstituição, coexistência e liberdade de situação. Parse apresenta nove pressupostos originais sintetizados em três. $\mathrm{O}$ primeiro coloca que a estrutura teórica Homem-Vida-Saúde dá significado pessoal para as situações vivenciadas, e isso reflete os valores pessoais do ser, que só o é pelo intercâmbio sujeito-sujeito. Dessa maneira, o ser humano assume a responsabilidade pelas suas decisões, no processo intersubjetivo de relacionar prioridades de valor entre estas a saúde. Esse é um processo aberto de vir a ser. O segundo agrupamento traz que o Homem-Vida-Saúde cocria padrões rítmicos de relacionamento, no intercâmbio aberto com o ambiente. Isso porque o ser humano é uma unidade viva, que continuamente coconstitui padrões de relacionamento, e a saúde é um processo ritmicamente coconstitutivo da inter-relação homem-ambiente. O terceiro grupo expressa que o Homem-Vida-Saúde é além do self. Ele é em todos os níveis do universo, à medida que os sonhos se tornam realidade. O ser humano transcende o que é possível nos vários níveis do universo. A saúde atua contra a desordem do homem unitário e tem participação crescente com o mundo. Assim, o ser humano evolui reciprocamente com o ambiente, participa na cocriação da saúde pessoal e confere significados às experiências, que refletem sonhos e esperanças (Hickman, 2000).

Madeleine Leininger: Refere-se aos seres humanos como seres homens. Eles são provedores de cuidados e capazes de preocupar-se com as necessidades relacionadas ao bemestar e à vivência dos outros. O cuidado com o homem é universal e encontrado em todas as culturas. Os humanos sobreviveram ao longo da história porque cuidaram uns dos outros de inúmeras maneiras, em variados ambientes, em diferentes tempos (George, 2000h).

Margaret Newman: Fala que a saúde engloba o todo da doença e o da não doença, ou seja, é uma totalidade indivisível. A doença é uma manifestação da saúde, não algo negativo ou em contraponto a ela. A saúde reconhece a existência de padrões, que são movimentos 


\section{pro.posıções}

e-ISSN 1980-6248

http://dx.doi.org/10.1590/1980-6248-2015-0164

constantes de partes diversas, com um ritmo que os identifica. A consciência se estende no universo em que habita toda a matéria, expandindo-se continuamente em direção a uma maior complexidade. Ela se constitui na habilidade de interação com o ambiente. O padrão de consciência é representado pelo encontro de tempo, espaço e movimento. O ser humano vê-se diante de seus próprios recursos internos, da qualidade de suas relações e da capacidade de viver no presente. A tarefa da enfermagem não é buscar a mudança dos padrões dos indivíduos, mas reconhecê-los e relacionar-se com eles. É estar em contato com o padrão próprio de alguém (George, 2000i).

Wanda Aguiar Horta: Fala que o ser "é aquilo que é, é a realidade" (Horta, 1979, p.3). Horta realizou a distinção de três seres: o Ser-Enfermeiro, o Ser-Cliente e o Ser-Enfermagem. Ao primeiro, ela se refere como um ser humano com todas as suas dimensões, aberto para o futuro e para a vida. "O Ser-Enfermeiro é gente que cuida de gente" (Horta, 1979, p.3). Em relação ao segundo, ela diz que os clientes podem ser indivíduos, famílias ou comunidades. São seres humanos que precisam ser cuidados por outros seres humanos, em qualquer fase do ciclo vital e do processo saúde-doença. É da interação entre o Ser-Enfermeiro com o Ser-Cliente, que surge o Ser-Enfermagem. Ele existe para que o Ser-Enfermeiro assista as necessidades humanas básicas do Ser-Cliente. O SerEnfermeiro é abstrato e transcendente. Com isso Horta quer dizer que a função do Ser-Enfermagem ultrapassa a questão do cuidado. Para ela, isso tem a ver com "estar comprometido, engajado na profissão. É compartilhar com cada ser humano sob seus cuidados a experiência vivenciada em cada momento. É usar-se terapeuticamente" (Horta, 1979, p.4).

Traçar esse caminho possibilitou a verificação de que as teoristas de enfermagem têm uma abordagem abrangente das questões humanas. Elas fazem apontamentos que se aproximam de diversos conteúdos, como: a existência humana; o ser no universo; o tempoespaço; o self; a imagem corporal; as relações interpessoais e ambientais; os seres como provedores de cuidado; os seres compreendidos como sistemas abertos; os seres que representam mais do que a soma de suas partes, entre outros. 


\section{pro.posıções}

http://dx.doi.org/10.1590/1980-6248-2015-0164

\section{$e$-ISSN 1980-6248}

\section{Discussão}

Várias teoristas de enfermagem se aproximaram do primeiro aspecto do "Ensino da condição humana", que trata do enraizamento/desenraizamento bumano. São elas: Nightingale (Lobo, 2000b), King (George, 2000e), Rogers (Falco \& Lobo, 2000), Fitzpatrick (George, 2000f), Roy (Galbreath, 2000), Neuman (George, 2000b), Parse (Hickman, 2000), e Newman (George, 2000i). Nesse ponto do pensamento de Morin, encontramos a ideia de que os humanos pertencem ao mesmo cosmos e ao planeta (Morin, 2011).

Desde Florence (Lobo, 2000b), há a premissa de que o ambiente influencia a condição humana. Para King (George, 2000e), os seres humanos constituem-se em sistemas abertos em constante interação com o seu meio ambiente. A percepção universal é experimentada por todos, é subjetiva ou pessoal e seletiva para cada pessoa. Segundo Rogers (Falco \& Lobo, 2000) e Roy (Galbreath, 2000), o ser humano troca informações, matérias e energia com o seu ambiente, o que resulta em respostas que geram mudanças internas e externas no homem. Esse, por sua vez, adapta-se continuamente ao ambiente. Para Neuman (George, 2000b), é por meio da interação com as forças internas e externas, que caracterizam o ambiente, que o ser humano retém graus variáveis de equilíbrio e harmonia. $\mathrm{O}$ ambiente intra, inter e extrapessoal opera o sistema do cliente.

Vale ressaltar que o movimento que fizemos foi uma aproximação da ideia que compõe a teoria ao primeiro princípio do ensino da condição humana. Assim, nem sempre as teoristas trabalharam o enraizamento/desenraizamento bumano de maneira tão semelhante à proposta de Morin. O autor discorre sobre os princípios biofísico e psicossociocultural humanos, remetendo um ao outro. Para ele, a animalidade e a humanidade constituem, juntas, a condição humana (Morin, 2011, p.51). Morin (2011) defende ainda que, como seres vivos, devemos assumir a nossa identidade terrena, física e biológica.

Destacamos a teorista Imogene King. Ela se aproxima dessa ideia, quando defende que as pessoas são sistemas abertos que aprendem e se comportam de diferentes maneiras, pela interação com o ambiente, consigo próprio e entre as pessoas. Para King, isso dá significado à experiência, pois representa a imagem da realidade que se possui, além de influenciar o comportamento humano (George, 2000e). 


\section{pro.posıções}

$e$-ISSN 1980-6248

http://dx.doi.org/10.1590/1980-6248-2015-0164

O segundo aspecto do "Ensino da condição humana" trata do bumano do bumano. Ele aborda a unidualidade do ser, que é plenamente biológico e cultural, simultaneamente. O humano é integralmente biológico, mas, se não fosse a cultura, seria um primata. A reprodução humana é responsável pelo aparecimento do indivíduo, que, em sua interação com outros, origina a sociedade. A sociedade, por sua vez, é a responsável pelo aparecimento da cultura, que retroage no indivíduo (Morin, 2011).

Essa premissa foi encontrada em todas as teoristas em estudo, com exceção de Florence Nightingale. Isso pode ser justificado pelo fato de a sua teoria ser a mais antiga da história da enfermagem, sendo escrita no século XIX, época em que o ambiente começou a ser considerado no tratamento em enfermagem.

Destacamos algumas teoristas que trabalharam com questões relacionadas às necessidades biopsicossocioculturais do ser humano cuidado pela enfermagem. Peplau refere que o homem é um organismo que luta para reduzir as tensões geradas por suas necessidades (Belcher \& Fish, 2000, p.47). Henderson diz que seres humanos são possuidores de necessidades básicas, satisfeitas por diversos padrões de vida (Furukawa \& Howe, 2000). Horta (1979) referese ao Ser-Enfermagem, como o resultante de uma interação em que o Ser-Enfermeiro satisfaz as necessidades humanas básicas do Ser-Cliente. Para Orlando, os enfermeiros precisam certificar-se de que as suas ações satisfarão as necessidades dos pacientes, quando eles não conseguirem (Leonard \& George, 2000). Wiedenbach e Orem falam que o ser humano necessita de estímulo para desenvolver as suas capacidades e autoestima (Bennett \& Foster, 2000; Foster \& Bennett, 2000).

Com ideias conexas a essas afirmações, Morin (2011) diz que todo desenvolvimento verdadeiramente humano significa o desenvolvimento conjunto das autonomias individuais, das participações comunitárias e do sentimento de pertencer à espécie humana.

Hall defende a ideia de que cada pessoa é diferente e, por isso, as ações de enfermagem devem ser individualizadas (George, 2000a). Orlando utiliza o conceito de ser humano, na medida em que enfatiza a individualidade e a natureza dinâmica da relação enfermeiro-paciente (Leonard \& George, 2000). Esse vínculo ativo também é encontrado em Horta (Horta, 1979). Rogers complementa que o humano possui integridade individual e que cada homem é unificado com individualidade (Falco \& Lobo, 2000). Para King, a cultura exerce impacto sobre o processo 


\section{pro.posições}

$e$-ISSN 1980-6248

http://dx.doi.org/10.1590/1980-6248-2015-0164

saúde-doença e sobre o profissional enfermeiro, que reconfigura seu modo de cuidar, afetando o indivíduo e seu modo de lidar com a doença (George, 2000e).

O pensamento de E. Morin (2011) é concordante com essa ideia. Para ele, o homo sapiens só se realiza de maneira plena na e pela cultura. Sem ela, o ser humano seria um primata. A cultura se produz pela complexificação do indivíduo e da sociedade.

Leininger traz à tona a questão do humano como um ser diverso, que é, ao mesmo tempo, singular e múltiplo e traz em si o cosmos e constitui-se dele (George, 2000h). Essa ideia é fronteiriça tanto com o enraizamento/desenraizamento bumano, quanto com unitas multiplex, que falam da diversidade humana, como exposto a seguir:

Morin (2011) diz que compreender o humano é compreender sua unidade na diversidade e sua diversidade na unidade. É preciso conceber a unidade do múltiplo e a diversidade do uno. Uma das vocações essenciais da educação do futuro proposta por Morin é o estudo da complexidade, que abranja as questões humanas em um sistema complexo e concomitantemente unificado. Assim, a educação deve ilustrar o destino multifacetado do humano: o destino da espécie humana, individual, social, histórico - todos entrelaçados e inseparáveis (Morin, 2011).

Algumas teoristas de enfermagem que corroboraram essa ideia são: Orem (Foster \& Bennett, 2000) Levine (Leonard, 2000), Rogers (Falco \& Lobo, 2000), Fitzpatrick (George, 2000f), Roy (Galbreath, 2000), Newman (George, 2000i) e Parse (Hickman, 2000). Dessas, somente Levine (Leonard, 2000) abrange apenas os aspectos do bumano do bumano e das unitas multiplex em seus pressupostos. As demais teoristas abordam os três aspectos do ensino da condição humana. Isso acontece porque as unitas trazem um apanhado de conteúdos pertencentes aos demais aspectos. Elas detêm a complexidade tanto no sentido do que é tecido junto quanto na profundidade dos eventos estudados.

Em relação à diversidade que as unitas propõem, Orem dá enfoque, em suas premissas, à diferença entre estrutura e função do humano (Foster \& Bennett, 2000). Fitzpatrick defende que o desenvolvimento humano é baseado em significados pessoais (George, 2000f). Newman relata que a tarefa da enfermagem é estar em contato com o padrão próprio de alguém (George, 2000i). 


\section{pro.posições}

$e$-ISSN 1980-6248

http://dx.doi.org/10.1590/1980-6248-2015-0164

Sobre as diferenças entres os humanos, Morin aborda a diversidade tanto nas questões biológicas, como nas comportamentais humanas. Para ele existem diferenças morfológicas e somáticas, conforme a herança genética e étnica do ser, e as condições climáticas modificam a fisiologia humana. O autor afirma que a infância e a adolescência representam um longo período de plasticidade, desconhecida dos outros seres vivos, e que a diversidade psicológica é ainda mais surpreendente que a física. Para ele personalidades, caracteres, temperamentos, sensibilidades e humor são imensamente varáveis. Morin afirma que os sistemas de ideias são bastante diferentes, dependendo das culturas e dentro delas. A própria consciência é múltipla e muda conforme as condições culturais (Morin, 2011).

Além dos aspectos do ensino da condição humana, as teoristas de enfermagem se aproximaram de mais alguns pressupostos do pensamento de Edgar Morin, dentre eles o da totalidade. Para Martha Rogers, o humano é um todo unificado, maior do que a soma das partes e diferentes delas (Falco \& Lobo, 2000). Essa ideia de que a totalidade não é uma mera somatória de seus componentes também está presente na teoria de Fitzpatrick (George, 2000f), Neuman (George, 2000b) e Watson (Talento, 2000) e corrobora o que Morin traz à tona em sua obra em inúmeras ocasiões. É preciso efetivamente recompor o todo para conhecer as partes (Morin, 2011).

O ser humano é sujeito e objeto de trabalho na enfermagem, ao mesmo tempo em que é único e diverso. Logo, a enfermagem deve considerá-lo em sua totalidade, respeitar o modo de viver de cada pessoa e as suas particularidades, procurar compreender as diversas influências e determinações que poderão induzir o seu modo de ser no mundo.

\section{Considerações finais}

Os resultados deste estudo mostraram que os corpos teóricos das teoristas de enfermagem contribuem para o alcance da complexidade e da totalidade do ser, porém existe uma maior abordagem do segundo aspecto do "Ensino da condição humana", o bumano do bumano. Das 23 teorias de enfermagem contempladas neste estudo, 22 abordaram esse aspecto. Esse é um dado significativo, porque aponta para o fato de as teoristas conferirem importância para as características individuais do humano e para a sua unidualidade. 


\section{pro.posıções}

$e$-ISSN 1980-6248

http://dx.doi.org/10.1590/1980-6248-2015-0164

Apesar de esse princípio ter sido abordado de maneira satisfatória, recomendamos que as escolas de enfermagem despendam atenção para as questões cósmicas e ecológicas abordadas no enraizamento/desenraizamento bumano, já que são de ordem contemporânea e nos situam como cidadãos desse planeta, pertencentes a um cosmos comum a todos.

O terceiro aspecto do ensino da condição humana, unitas multiplex, que diz respeito à diversidade, não recebeu tanto destaque pelas teoristas de enfermagem, assim como o primeiro princípio. Portanto, também recomendamos que as questões de diversidade e pluralidade de indivíduos sejam trabalhadas de maneira mais profundas, durante a formação em enfermagem, de modo a favorecer a consciência de que, embora pareçamos, não somos exatamente iguais. A expansão da consciência para esse entendimento favorece a compreensão e a solidariedade humana. Isso, por sua vez, reflete no cuidado de enfermagem.

A educação de enfermagem deve ilustrar o destino multifacetado do humano, o destino da espécie humana: individual, social e histórico, todos entrelaçados e inseparáveis, constituindo um tecido complexo. Uma das vocações essenciais da educação do futuro proposta por Morin fala do estudo da complexidade humana (Morin, 2005).

Podemos concluir que os corpos teóricos das teoristas de enfermagem buscaram aproximar-se da complexidade e estabelecer conhecimentos que orientassem a prática do enfermeiro para a formação de uma consciência da condição humana comum a todos, necessária à diversidade da sociedade, e que permitissem o desenvolvimento da cidadania e do cuidado humano, de maneira integrada e condizente ao nosso enraizamento como cidadãos da Terra. 


\section{pro.posıções}

$e$-ISSN 1980-6248

http://dx.doi.org/10.1590/1980-6248-2015-0164

\section{Referências}

Almeida, M. C. P. de, Mishima, S. M., Pereira, M. J., Bistafa, Palha, P. F., Villa, T. C. S., ..., \& Matumoto, S. (2009, setembro/outubro) Enfermagem enquanto disciplina: que campo de conhecimento identifica a profissão? Revista Brasileira de Enfermagem, 62(5),748752.

Ângelo, M., Forcella, H. T., \& Fukuda, I. M. K. (1995, agosto). Do empirismo à ciência: a evolução do conhecimento de enfermagem. Revista da Escola de Enfermagem da USP, 29(2), 211-223.

Belcher, J. R., \& Fish, L. J. B. (2000). Hildegard E. Peplau. In J. B. George, Teorias de enfermagem: os fundamentos para a prática profissional (pp. 45-58, 4a ed). Porto Alegre: Artes Médicas.

Bennett, A. M., \& Foster, P. C. (2000). Peggy Coldwell. Ernestine Wiedenbach. In J. B. George, Teorias de enfermagem: os fundamentos para a prática profissional (pp. 147-158, 4a ed). Porto Alegre: Artes Médicas

Dell'Aqua, M. C. Q., \& Myadahira, A.M. K. (2002, março/abril). Ensino do processo de enfermagem nas escolas de graduação em enfermagem do estado de São Paulo. Revista Latino-Americana de Enfermagem, 10(2),185-191.

Falco, S.M. F. (2000). Glenn Abdellah. In J. B. George, Teorias de enfermagem: os fundamentos para a prática profissional (pp. 119-130, 4a ed). Porto Alegre: Artes Médicas

Falco, S.M., \& Lobo, M. L. (2000). Martha E. Rogers. In J. B. George, Teorias de enfermagem: os fundamentos para a prática profissional (pp. 185-200, 4a ed). Porto Alegre: Artes Médicas.

Fernandes, J. D., \& Rebouças, L. C. (2013). Uma década de Diretrizes Curriculares Nacionais para a Graduação em Enfermagem: avanços e desafios. Revista. Brasileira de Enfermagem, 66 (n. esp.), 95-101.

Foster, P. C., \& Benett, A. M. (2000). Dorothea E. Orem. In J. B. George, Teorias de enfermagem: os fundamentos para a prática profissional (pp. 83-102, 4a ed.). Porto Alegre: Artes Médicas. 


\section{pro.posıções}

$e$-ISSN 1980-6248

http://dx.doi.org/10.1590/1980-6248-2015-0164

Furukawa, C. Y., \& Howe, J. K. (2000). Virgínia Henderson. In J. B. George, Teorias de enfermagem: os fundamentos para a prática profissional (pp. 59-72, 4a ed.). Porto Alegre: Artes Médicas.

Galbreath, J. G. (2000). Callista Roy. In J. B. George, Teorias de enfermagem: os fundamentos para a prática profissional (pp. 203-224, 4a ed). Porto Alegre: Artes Médicas.

Garcia, T. R., \& Nóbrega, M. M. L. (2004, março/abril). Contribuição das teorias de enfermagem para a construção do conhecimento da área. Revista Brasileira de Enfermagem, 57(2), 228-232.

George, J. B. (1993). Teorias de enfermagem: os fundamentos para a prática profissional (3a ed.). Porto Alegre: Artes Médicas.

George, J. B. (2000a). Betty Jo-Hadley. In J. B. George, Teorias de enfermagem: os fundamentos para a prática profissional (pp. 115-118, 4a ed.). Porto Alegre: Artes Médicas.

George, J. (2000b). Betty Neuman. In J. B. George, Teorias de enfermagem: os fundamentos para a prática profissional (pp. 225-240, 4a ed.). Porto Alegre: Artes Médicas.

George, J. B. (2000c). Evelyn Adam. In J. B. George, Teorias de enfermagem: os fundamentos para a prática profissional (pp. 73-74, 4a ed.). Porto Alegre: Artes Médicas.

George, J. B. (2000d). Ida Orlando. In J. B. George, Teorias de enfermagem: os fundamentos para a prática profissional (pp. 75-82, 4a ed.). Porto Alegre: Artes Médicas.

George, J. B. (2000e). Imogene King. In J. B. George, Teorias de enfermagem: os fundamentos para a prática profissional (pp. 169-184, 4a ed.). Porto Alegre: Artes Médicas.

George, J. B. (2000f). Joyce Fitzpatrick. In J. B. George, Teorias de enfermagem: os fundamentos para a prática profissional (pp. 201-202, 4a ed.). Porto Alegre: Artes Médicas.

George, J. B. (2000g). Lydia E. Hall. In J. B. George, Teorias de enfermagem: os fundamentos para a prática profissional (pp. 75-82, 4a ed.). Porto Alegre: Artes Médicas.

George, J. B. (2000h). Madeleine Leininger. In J. B. George, Teorias de enfermagem: os fundamentos para a prática profissional (pp. 297-310, 4a ed.). Porto Alegre: Artes Médicas. 


\section{pro.posıções}

$e$-ISSN 1980-6248

http://dx.doi.org/10.1590/1980-6248-2015-0164

George, J. B. (2000i). Margaret Newman. In J. B. George, Teorias de enfermagem: os fundamentos para a prática profissional (pp. 311-322, 4a ed.). Porto Alegre: Artes Médicas

Gil, A. C. (2002). Como elaborar projetos de pesquisa (4a ed.). São Paulo: Atlas.

Hickman, J. S. (2000). Rosemarie Rizzo Parse. In J. B. George, Teorias de enfermagem: os fundamentos para a prática profissional (pp. 267-282, 4a ed.). Porto Alegre: Artes Médicas.

Horr, L., Gonçalves, L. H. T., \& Saupe, R. (1987). O ensino da metodologia assistencial de enfermagem-departamento de enfermagem - UFSC. Revista da Escola de Enfermagem da USP, 21(n. esp.), 1-8.

Horta, W. A. (1979). Processo de Enfermagem. São Paulo: EPU.

Leonard, M.K. (2000). Myra Estrin Levine. In J. B. George, Teorias de enfermagem: os fundamentos para a prática profissional (pp. 159-168, 4a ed.). Porto Alegre: Artes Médicas.

Leonard, M.K., \& George, J. B. (2000). Ida Jean Orlando. In J. B. George, Teorias de enfermagem: os fundamentos para a prática profissional (pp. 131-146, 4a ed). Porto Alegre: Artes Médicas.

Lobo, M. L. (2000a). Dorothy E. Johnson. In J. B. George, Teorias de enfermagem: os fundamentos para a prática profissional (pp. 102-114, 4a ed.). Porto Alegre: Artes Médicas.

Lobo, M. L. (2000b). Florence Nightingale. In J. B. George, Teorias de enfermagem: os fundamentos para a prática profissional (pp. 267-282, 4a ed.). Porto Alegre: Artes Médicas.

Morin, E. (2005). Introdução ao pensamento complexo (E. Lisboa, trad., Introduction à la pensée complexe, trad.). Porto Alegre: Sulina.

Morin, E. (2011). Ensinar a condição humana. In E. Morin, Os sete saberes necessários para a educação do futuro (pp. 47-59, 2a ed.). Brasília: UNESCO 


\section{pro.posıções}

$e$-ISSN 1980-6248

http://dx.doi.org/10.1590/1980-6248-2015-0164

Pires, S. M. B., Méier, M. J., \& Danski, M. T. R.. (2011, janeiro/julho). Fragmentos da trajetória pessoal e profissional de Wanda Horta: contribuições para a área de enfermagem. História de Enfermagem. Revista Eletrônica, 2(1), 1-15.

Praeger, S, G. (2000), Josephine E. Paterson e Loretta T. Zderad. In J. B. George, Teorias de enfermagem: os fundamentos para a prática profissional (pp. 241-252, 4a ed.). Porto Alegre: Artes Médicas.

Schaurich, D., \& Crossetti, M. da G. O. (2010, março). Produção do conhecimento sobre teorias de enfermagem: análise de periódicos da área, 1998-2007. Escola Anna Nery, Rio de Janeiro, 14(1), 182-188.

Silva, E. N. da. (2014). Pensamento curricular contemporâneo na formação dos cursos de graduação em enfermagem em universidades públicas. Dissertação de Mestrado Profissional em Ensino na Saúde, Universidade Federal de Alagoas, Maceió.

Sitó, J. A. da S. (2005). Projeto político pedagógico: um exercício de construção sistêmica e complexa. Retirado em 2 de fevereiro de 2014, de http://docplayer.com.br/8618714Projeto-politico-pedagogico-um-exercicio-de-construcao-sistemica-e-complexa-1.html.

Talento, B. (2000). Jean Watson. In J. B. George, Teorias de enfermagem: os fundamentos para a prática profissional (pp. 253-266, 4a ed.). Porto Alegre: Artes Médicas.

Thofehrn, M. B., \& Leopardi, M. T. (2002, janeiro/abril). Teorias de enfermagem, trabalho e conhecimento contemporâneo. Texto\&Contexto-Enferm, 1(1), 86-104.

Submetido à avaliação em 3 de dezembro de 2015; revisado em 20 de setembro de 2016; aceito para publicação em 6 de outubro de 2016. 